\title{
Trends in the epidemiology of smoking recorded in UK general practice
}

Colin R Simpson, Julia Hippisley-Cox and Aziz Sheikh

\author{
ABSTRACT \\ Background \\ Smoking represents the most important cause of \\ avoidable morbidity and mortality in the economically \\ developed world. The UK has recently introduced a \\ range of initiatives aiming to reduce smoking \\ prevalence and smoking-related health inequalities. \\ Aim \\ To investigate the epidemiology of smoking in UK \\ general practice. \\ Design of study \\ Cross-sectional study. \\ Setting \\ A total of 525 general practices contributing to the \\ QRESEARCH database. \\ Method \\ A dataset was extracted on 2.7 million patients around \\ each financial year for the period 2001-2007, including, \\ age, sex, deprivation, and smoking status. For patients \\ newly recorded as smoking, data were extracted on \\ receipt of smoking cessation advice and referral to \\ stop-smoking services. \\ Results \\ Over the study period, the proportion of people with \\ smoking status recorded increased by $32.9 \%$ \\ (2001/2002: $46.6 \%$ to 2006/2007: 79.5\%). A large \\ overall increase in the provision of smoking cessation \\ advice (2001/2002: $43.6 \%$ to 2006/2007: $84.0 \%$ ) and \\ referral to stop-smoking services (2001/2002: $1.0 \%$ to \\ 2006/2007: 6.6\%) was also observed. The proportion \\ of people who smoked (with a recorded smoking \\ status) reduced by $6.0 \%$ (2001/2002: $28.4 \%$ to \\ 2006/2007: 22.4\%). This decrease was greatest among \\ patients in the most deprived areas $(7.2 \%)$ and the \\ youngest patients (16-25 years: $7.1 \%$ ). In 2006/2007, \\ more than twice as many patients in deprived areas \\ smoked as those in affluent areas (most deprived: \\ $33.8 \%$; most affluent: $14.1 \%$ ).

\section{Conclusion} \\ A significant and important reduction in the number of \\ UK smokers occurred between April 2001 and April \\ 2007. However, although this is an improvement, \\ comparatively high rates of smoking remain among \\ younger adults and those who are the most \\ socioeconomically deprived.

\section{Keywords} \\ epidemiology; general practice; QRESEARCH; \\ smoking; socioeconomic status.
}

\section{INTRODUCTION}

In 1972, almost half of the UK adult population was found to smoke. Over the next two decades, this reduced dramatically to less than one-third. However, in the 1990s the decline in the rate of smoking slowed. ${ }^{1}$ The White Paper on tobacco, Smoking Kills, ${ }^{2}$ and the command paper, The NHS Plan: a plan for investment, a plan for reform, ${ }^{3}$ published in 1998 and 2000 respectively, highlighted that smoking was the principal avoidable cause of premature death in the UK, and drew attention to the fact that the most vulnerable in society were most likely to suffer from the adverse effects of smoking.

The government's multifaceted plans (introduced in 1999) to reduce smoking included a $£ 50$ million ( $€ 60$ million) publicity campaign to shift attitudes and change behaviour; a substantial increase in tax to reduce the affordability of smoking; a $£ 35$ million ( $€ 42$ million) investment in customs to reduce tobacco smuggling; and a £60 million ( $€ 72$ million) smoking cessation service provided by the NHS. This latter initiative included the introduction of prescribing of nicotine replacement therapy and other smoking cessation treatments, and an increase in specialist cessation services for the most heavily dependent smokers. A European-wide banning of smoking advertising was endorsed, and

CR Simpson, PhD, senior research fellow; $A$ Sheikh, $P h D$, professor of primary care R\&D, Allergy and Respiratory Research Group, Centre for Population Health Sciences, University of Edinburgh. J Hippisley-Cox, MD, FRCP, FRCGP, professor of clinical epidemiology and general practice, Community Health Sciences, University of Nottingham.

Address for correspondence

Colin Simpson, Allergy and Respiratory Research Group, Centre for Population Health Sciences, University of Edinburgh, Medical School, Teviot Place, Edinburgh EH8 9AG. E-mail: c.simpson@ed.ac.uk

Submitted: 17 June 2009; Editor's response: 11 August 2009; final acceptance: 14 August 2009.

(C) British Journal of General Practice

This is the full-length article of an abridged version published in print. Cite this article as: Br J Gen Pract 2010; 10.3399/bjgp10X483544 
the Tobacco Advertising and Promotion Act 2002 passed to create a timetable for the ban on tobacco advertising and sponsorship, such that by 31 July 2005 most tobacco advertising and sponsorship would cease.

In April 2004, a quality-based General Medical Services (GMS) contract was introduced into UK primary care. ${ }^{4}$ This new contract reduced the proportion of income GPs derived from per capita payments and increased the proportion derived from the recording of patient information (usually onto electronic patient records) and implementation of good quality of care. An average practice could be paid $£ 1371$ (€1577) if smoking status was recorded in at least $75 \%$ of registered patients aged $15-75$ years. Further income (a mean of £8724; $€ 10033$ per practice) could be generated if smoking status was recorded in patients with chronic diseases (such as diabetes or coronary heart disease), and smoking cessation support was provided to patients who smoked (assuming a payment of $£ 124.60 ; € 143.30$ per quality outcome framework point). The introduction of these figures meant that by 2006 , the UK was considered to be the second most effective country in the European Union (behind the Republic of Ireland) for implementing tobacco control policies. ${ }^{5}$

The current government has repeatedly acknowledged the wide gap between health needs and service delivery, and highlighted that the reduction in the socioeconomic gradient in smoking is probably the single most effective thing government can do to reduce inequalities in health. This has led to the targeting of resources towards the reduction of these socioeconomic health inequalities. ${ }^{6}$ Thus, commissioners and providers of health care are, for example, now assessed in relation to the extent to which they are successful in reducing smoking inequalities. ${ }^{7}$

Large electronic national healthcare datasets, with their key strengths of large numbers and representative data, can offer an important method for monitoring trends in smoking and also provide important insights into the impact of the new GMS contract. With individual patient-level data available, inequalities between different groups of patients can also be determined. Building on previous work with the Information Centre for Health and Social Care, ${ }^{8-12}$ this study sought to confirm the recent acceleration in smoking reduction found using survey data, ${ }^{1}$ and also describe the recording of smoking status, provision of smoking advice, and referral to specialist stop-smoking services in patients registered in primary care in the UK. It also aimed to investigate whether these trends differed between sex, age, and deprivation groups.

\section{How this fits in}

The UK has recently introduced initiatives aiming to reduce smoking prevalence and smoking-related health inequalities. A significant and important increase in the recording of smoking status and issuing of smoking cessation advice by general practice in the UK occurred between April 2001 and April 2007. There was also a reduction in the proportion of people found to smoke. However, comparatively high rates of smoking remain among younger adults and those who are the most socioeconomically deprived. There is a continued need to focus greater resources and efforts on targeting the prevention of smoking uptake in children and adolescents and providing more resources for smoking cessation services aimed at younger and socioeconomically-deprived adults.

\section{METHOD}

Version 10 of the QRESEARCH database was used for this analysis. This database contains representative anonymised aggregated health data derived from 525 general practices. Although these practices are self-selected, they are broadly representative of primary care practices in the UK..$^{13}$ Data were extracted for the period 1 April 2001 (2 708917 patients) to 1 April 2007 (2 708867 patients). The same practices were used throughout the study period. These data were used in the published report: A Summary of Public Health Indicators using Electronic Data from Primary Care, ${ }^{9}$ and are freely available in aggregate form from the QRESEARCH website. ${ }^{14}$ The methods used to collect primary care data for the QRESEARCH database have been previously described. ${ }^{8}$

In the UK the majority of individuals resident (including children) are registered with primary care, which is free at the point of contact. Patients were included if they were registered on 1 April each year and were registered for the preceding 12 months and aged 16 years or over. For simplicity, the financial year April 2001 to April 2002 is represented as 2001/2002 and April 2006 to April 2007 as $2006 / 2007$. Those with incomplete data (temporary residents, newly registered patients, and those who joined, left, or died during the study year) were excluded.

Smokers were defined as the proportion of patients with smoking status code (Read Code: 137 and below) in the last 5 years recorded as a current smoker (in the year of study). To estimate the actual number of people who smoked in the UK, the data were scaled up, using the UK 2001 Census and midyear population estimates. ${ }^{15}$ For patients who had been recorded as smokers in the previous 12 months researchers determined the in-house smoking cessation advice provided (Read Codes: 6791, 67A3, 8B2B, 8CAL, 8HTK, 13p., 900., 9N4M, $9 \mathrm{~N} 2 \mathrm{k}, 8 \mathrm{H} 7 \mathrm{i}, 67 \mathrm{H} 1,8 \mathrm{~B} 3 \mathrm{Y}, 8 \mathrm{~B} 3 \mathrm{f})$ and referral to a stop-smoking specialist (Read Codes: $8 \mathrm{H} 7 \mathrm{i}$ and 
Table 1. Patients aged $>15$ years with smoking status recorded.

\begin{tabular}{|c|c|c|c|c|c|}
\hline & \multicolumn{2}{|c|}{ 2001/2002 } & \multicolumn{2}{|c|}{$2006 / 2007$} & \multirow[b]{2}{*}{$\%$ change $2001-2007$} \\
\hline & $n$ (total $n$ ) & $\%(95 \% \mathrm{Cl})$ & $n$ (total $n$ ) & $\%(95 \% \mathrm{Cl})$ & \\
\hline All patients & 1263496 (2 708 917) & 46.64 (46.58 to 46.70$)$ & 2154658 (2 708 867) & 79.54 (79.49 to 79.59$)$ & 32.90 \\
\hline \multicolumn{6}{|l|}{ Sex } \\
\hline Female & 726917 (1 374 252) & 52.90 (52.81 to 52.98 ) & 1176377 (1 367817$)$ & 86.00 (85.95 to 86.06 ) & 33.10 \\
\hline Male & 536579 (1 334665$)$ & $40.20(40.12$ to 40.29$)$ & 978281 (1 341050$)$ & 72.95 (72.87 to 73.02$)$ & 32.75 \\
\hline \multicolumn{6}{|c|}{ Age-band, years } \\
\hline $16-24$ & 129809 (331 782) & 39.12 (38.96 to 39.29 ) & 243516 (349 400) & 69.70 (69.54 to 69.85 ) & 30.58 \\
\hline $25-34$ & 241662 (450 280) & 53.67 (53.52 to 53.81$)$ & 322694 (412 811) & 78.17 (78.04 to 78.30$)$ & 24.50 \\
\hline $35-44$ & 241387 (529 104) & 45.62 (45.49 to 45.76$)$ & 390805 (523 909) & 74.59 (74.48 to 74.71$)$ & 28.97 \\
\hline $45-54$ & 195069 (441 617) & 44.17 (44.03 to 44.32$)$ & 347819 (450 530) & 77.20 (77.08 to 77.32$)$ & 33.03 \\
\hline $55-64$ & 186339 (389 128) & 47.89 (47.73 to 48.04$)$ & 340240 (408 567) & 83.28 (83.16 to 83.39 ) & 35.39 \\
\hline $65-74$ & 144796 (288 339) & $50.22(50.03$ to 50.40$)$ & 255073 (283 923) & 89.84 (89.73 to 89.95$)$ & 39.62 \\
\hline$\geq 75$ & 124434 (278 667) & 44.65 (44.47 to 44.84$)$ & 254511 (279 727) & 90.99 (90.88 to 91.09 ) & 46.34 \\
\hline \multicolumn{6}{|c|}{ Socioeconomic status ${ }^{a}$} \\
\hline Quintile 1 & 276107 (607 528) & 45.45 (45.32 to 45.57$)$ & 489931 (612 866) & 79.94 (79.84 to 80.04$)$ & 34.49 \\
\hline Quintile 2 & 247693 (539 442) & 45.92 (45.78 to 46.05$)$ & 435846 (544 339) & 80.07 (79.96 to 80.17$)$ & 34.15 \\
\hline Quintile 3 & 236964 (506 448) & 46.79 (46.65 to 46.93 ) & 412719 (513 362) & 80.40 (80.29 to 80.50$)$ & 33.61 \\
\hline Quintile 4 & 224884 (463 323) & 48.54 (48.39 to 48.68 ) & 375533 (467 692) & 80.29 (80.18 to 80.41$)$ & 31.75 \\
\hline Quintile 5 & 236925 (476 786) & 49.69 (49.55 to 49.83 ) & 395645 (496 427) & 79.70 (79.59 to 79.81$)$ & 30.01 \\
\hline
\end{tabular}

${ }^{a}$ Higher quintiles indicate areas of greater socioeconomic deprivation.

8HTK). Socioeconomic deprivation was defined on the basis of the Townsend score associated with the output area of the patient's postcode. The Townsend score is a composite score based on unemployment, overcrowding, lack of car ownership, and non-owner occupancy. Higher scores indicate greater levels of socioeconomic deprivation. The cut-offs for the quintiles are based on the national distribution of Townsend scores derived from the UK 2001 Census.

\section{Statistical methods}

The $\chi^{2}$ test was used to compare categorical variables in different groups of patients. The MantelHaenszel $\chi^{2}$ test was used to investigate trends over time, this analysis being undertaken using Epi Info2000 (Centers for Disease Control and
Prevention, Atlanta, US). Where appropriate, 95\% confidence intervals $(95 \% \mathrm{Cls})$ are reported.

\section{RESULTS}

\section{Smoking status recording}

In 2001/2002, women and people living in more deprived socioeconomic areas were most likely to have smoking status recorded $(P<0.001$; online Table 1). In 2006/2007, sex differences persisted, but no socioeconomic differences were apparent (Table 1). From 2001/2002 to 2006/2007, there was a highly significant increase in the recording of smoking status in all patients $(P<0.001$; Figure 1$)$, but most particularly in the oldest group of patients (Table 1), such that by $2006 / 2007$, the oldest age group had the highest proportion of patients with a smoking status recorded (Table 1).
Figure 1. Proportion of smokers, non-smokers, and patients with no smoking status recorded (2001-2007).

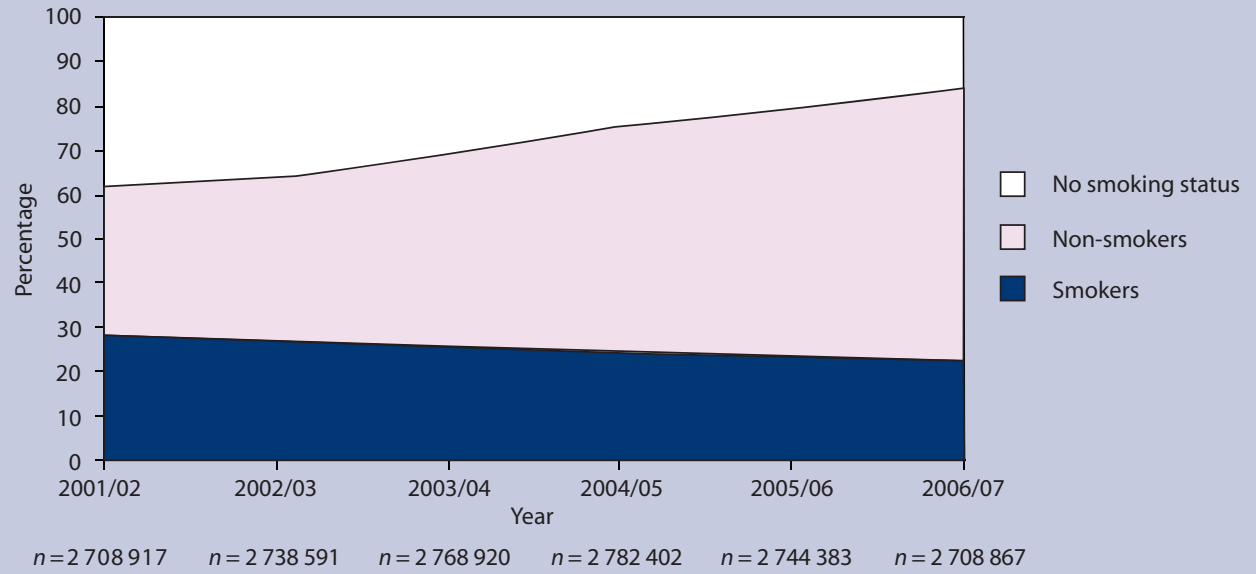


Table 2. Patients aged $>15$ years with smoking status recorded as smokers.

\begin{tabular}{|c|c|c|c|c|c|}
\hline & \multicolumn{2}{|c|}{ 2001/2002 } & \multicolumn{2}{|c|}{$2006 / 2007$} & \multirow[b]{2}{*}{$\%$ change $2001-2007$} \\
\hline & $n$ (total $n$ ) & $\%(95 \% \mathrm{Cl})$ & $n$ (total $n$ ) & $\%(95 \% \mathrm{Cl})$ & \\
\hline All patients & 358956 (1 263496$)$ & 28.41 (28.33 to 28.49 ) & 483239 (2 154658$)$ & 22.43 (22.37 to 22.48$)$ & -5.98 \\
\hline \multicolumn{6}{|l|}{ Sex } \\
\hline Female & 190219 (726 917) & 26.17 (26.07 to 26.27 ) & 235614 (1 176 377) & 20.03 (19.96 to 20.10$)$ & -6.14 \\
\hline Male & 168737 (536 579) & 31.45 (31.32 to 31.57$)$ & 247625 (978 281) & 25.31 (25.23 to 25.40$)$ & -6.14 \\
\hline \multicolumn{6}{|c|}{ Age-band, years } \\
\hline $16-24$ & 43089 (129 809) & 33.19 (32.94 to 33.45$)$ & 63565 (243 516) & 26.10 (25.93 to 26.28$)$ & -7.09 \\
\hline $25-34$ & 86209 (241 662) & 35.67 (35.48 to 35.86$)$ & 99748 (322 694) & 30.91 (30.75 to 31.07 ) & -4.76 \\
\hline $35-44$ & $76722(241387)$ & 31.78 (31.60 to 31.97$)$ & 107714 (390 805) & 27.56 (27.42 to 27.70$)$ & -4.22 \\
\hline $45-54$ & 60954 (195 069) & 31.25 (31.04 to 31.45$)$ & 87310 (347 819) & 25.10 (24.96 to 25.25$)$ & -6.15 \\
\hline $55-64$ & 49122 (186 339) & 26.36 (26.16 to 26.56$)$ & 69307 (340 240) & 20.37 (20.23 to 20.51$)$ & -5.99 \\
\hline $65-74$ & 27551 (144 796) & 19.03 (18.83 to 19.23$)$ & 35608 (255 073) & 13.96 (13.83 to 14.09$)$ & -5.07 \\
\hline$\geq 75$ & 15309 (124 434) & 12.30 (12.12 to 12.49$)$ & 19987 (254 511) & 7.85 (7.75 to 7.96$)$ & -4.45 \\
\hline \multicolumn{6}{|c|}{ Socioeconomic status ${ }^{a}$} \\
\hline Quintile 1 & 51861 (276 107) & 18.78 (18.64 to 18.93$)$ & 69242 (489 931) & 14.13 (14.04 to 14.23$)$ & -4.65 \\
\hline Quintile 2 & 55252 (247 693) & 22.31 (22.14 to 22.47$)$ & 75370 (435 846) & 17.29 (17.18 to 17.41$)$ & -5.02 \\
\hline Quintile 3 & 65491 (236 964) & 27.64 (27.46 to 27.82$)$ & 90364 (412 719) & 21.89 (21.77 to 22.02$)$ & -5.70 \\
\hline Quintile 4 & 76279 (224 884) & 33.92 (33.72 to 34.11$)$ & 104718 (375 533) & 27.89 (27.74 to 28.03$)$ & -6.03 \\
\hline Quintile 5 & 97221 (236 925) & 41.03 (40.84 to 41.23$)$ & 133806 (395 645) & 33.82 (33.67 to 33.97 ) & -7.21 \\
\hline
\end{tabular}

${ }^{a} H i g h e r$ quintiles indicate areas of greater socioeconomic deprivation.

\section{Smoking rates}

In both 2001/2002 and 2006/2007, the higher rates of smoking were found among males, younger patients, and those in the most deprived areas who had more than twice the rate of smoking than the most affluent patients $(P<0.001$; Table 2). In $2006 / 2007$, the highest prevalence of smoking was found among men aged 35-44 years who were in the most deprived group $(44.6 \% ; 95 \% \mathrm{Cl}=44.1$ to $45.1 ; n=16720$ of 37495$)$. There was a decrease over the study period in the proportion of people recorded as smokers $(P<0.001$; Figure 1$)$. This was most apparent in the youngest patients and those who lived in the most deprived areas (Table 2).

Based on the rates of smoking among patients registered to QRESEARCH practices, the estimated number of adult smokers in the UK in 2006/2007 was

$$
13676782(95 \% \mathrm{Cl}=13640197 \text { to } 13707270) .
$$

\section{Smoking cessation advice and referral to stop-smoking specialists}

In 2001/2002, male, older, and patients in deprived areas (who had been recorded as smokers in the last 12 months) received the most smoking cessation advice $(P<0.001$; Table 3$)$. However, although age differences persisted in 2006/2007, more women than men, and similar proportions from the most affluent and most deprived groups, were provided with smoking cessation advice (Table 3). In 2001/2002, patients in deprived areas were more likely to be referred to a specialist stopsmoking service $(P<0.001$; Table 4). In 2006/2007, those older patients and those living in the most deprived areas were most likely to be referred

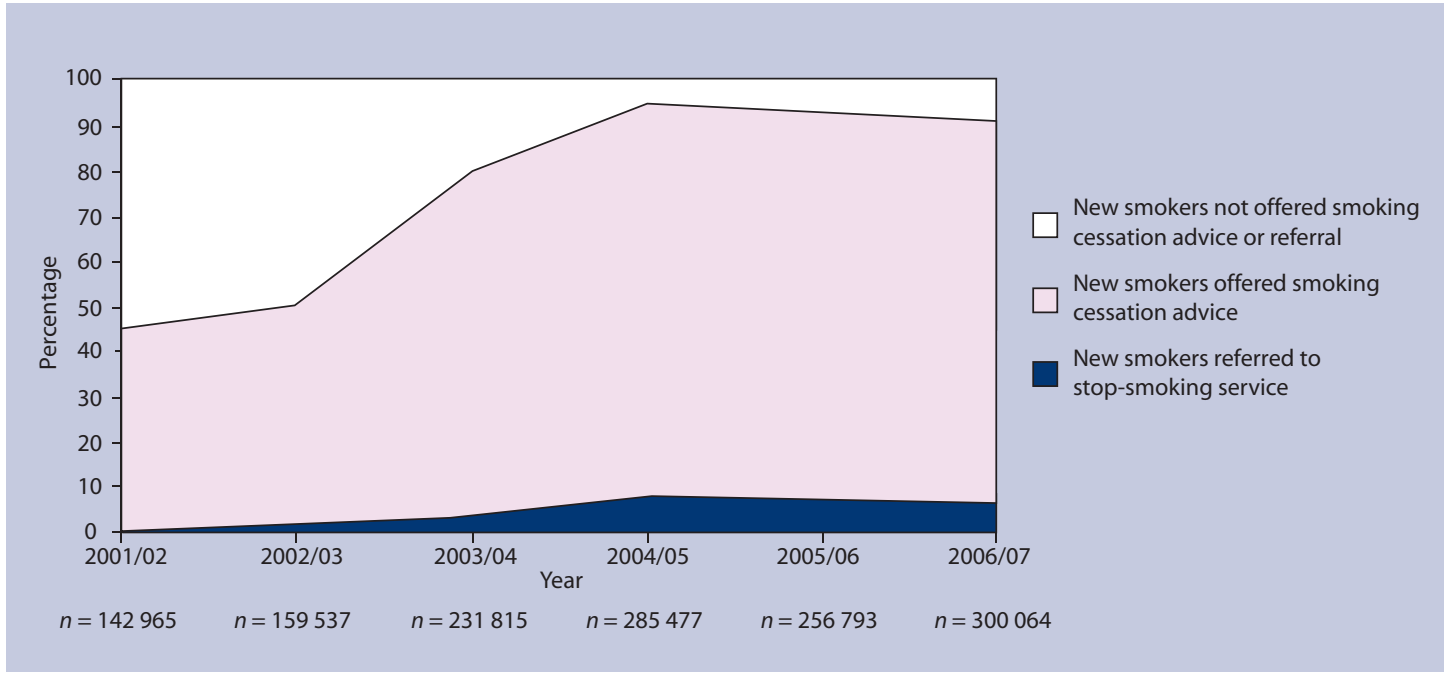

Figure 2. Proportion of new smokers (recorded in the previous 12 months) given smoking cessation advice or referred to stop-smoking service (2001-2007). 
Table 3. Patients aged $>15$ years recorded as smokers in the last 12 months who were provided with smoking cessation advice from primary care.

\begin{tabular}{|c|c|c|c|c|c|}
\hline & \multicolumn{2}{|c|}{$2001 / 2002$} & \multicolumn{2}{|c|}{$2006 / 2007$} & \multirow[b]{2}{*}{$\%$ change $2001-2007$} \\
\hline & $n$ (total $n$ ) & $\%(95 \% \mathrm{Cl})$ & $n$ (total $n$ ) & $\%(95 \% \mathrm{Cl})$ & \\
\hline All patients & 62393 (142 695) & 43.64 (43.39 to 43.90$)$ & 252042 (300 064) & 84.00 (83.87 to 84.13$)$ & 40.36 \\
\hline \multicolumn{6}{|l|}{ Sex } \\
\hline Female & 37441 (87 176) & 42.95 (42.62 to 43.28 ) & 138328 (162 614) & 85.07 (84.89 to 85.24$)$ & 42.12 \\
\hline Male & 24952 (55 789) & 44.73 (44.31 to 45.14$)$ & $113714(137450)$ & 82.73 (82.53 to 82.93 ) & 38.00 \\
\hline \multicolumn{6}{|c|}{ Age-band, years } \\
\hline $16-24$ & 7644 (19 307) & 39.59 (38.90 to 40.28$)$ & 31554 (38 358) & 82.26 (81.88 to 82.64$)$ & 42.67 \\
\hline $25-34$ & $11833(28$ 154) & 42.03 (41.45 to 42.61$)$ & 41401 (51 078) & 81.05 (80.71 to 81.39 ) & 39.02 \\
\hline $35-44$ & 11428 (25 859) & 44.19 (43.59 to 44.80$)$ & 48613 (59 697) & 81.43 (81.12 to 81.74$)$ & 37.24 \\
\hline $45-54$ & 11039 (24 452) & 45.15 (44.52 to 45.77$)$ & $45020(53541)$ & 84.09 (83.78 to 84.39 ) & 38.94 \\
\hline $55-64$ & 10772 (22 973) & 46.89 (46.24 to 47.54$)$ & 43054 (49 556) & 86.88 (86.58 to 87.18 ) & 39.99 \\
\hline $65-74$ & $6852(14551)$ & 47.09 (46.28 to 47.90$)$ & 26886 (30 197) & 89.03 (88.68 to 89.39$)$ & 41.94 \\
\hline$\geq 75$ & 2825 (7 669) & 36.84 (35.76 to 37.92$)$ & 15514 (17 637) & 87.96 (87.48 to 88.44$)$ & 51.12 \\
\hline \multicolumn{6}{|c|}{ Socioeconomic status ${ }^{a}$} \\
\hline Quintile 1 & 8943 (20 885) & $42.82(42.15$ to 43.49$)$ & 36219 (43 492) & 83.27 (82.93 to 83.63 ) & 40.45 \\
\hline Quintile 2 & 9726 (22 646) & 42.95 (42.30 to 43.59$)$ & 39586 (47 273) & 83.74 (83.41 to 84.07$)$ & 40.79 \\
\hline Quintile 3 & 11430 (26 699) & 42.81 (42.21 to 43.40$)$ & 47559 (56 809) & 83.71 (83.41 to 84.02 ) & 40.90 \\
\hline Quintile 4 & 13449 (30 386) & 44.26 (43.70 to 44.82$)$ & 54600 (64 663) & 84.44 (84.16 to 84.72 ) & 40.18 \\
\hline Quintile 5 & 16819 (37 278) & 45.12 (44.61 to 45.62$)$ & $68516(81598)$ & 83.97 (83.72 to 84.22$)$ & 38.85 \\
\hline
\end{tabular}

aHigher quintiles indicate areas of greater socioeconomic deprivation.

Table 4. Patients aged $>15$ years recorded as smokers in the last 12 months who were referred to a stopsmoking service in the last 12 months.

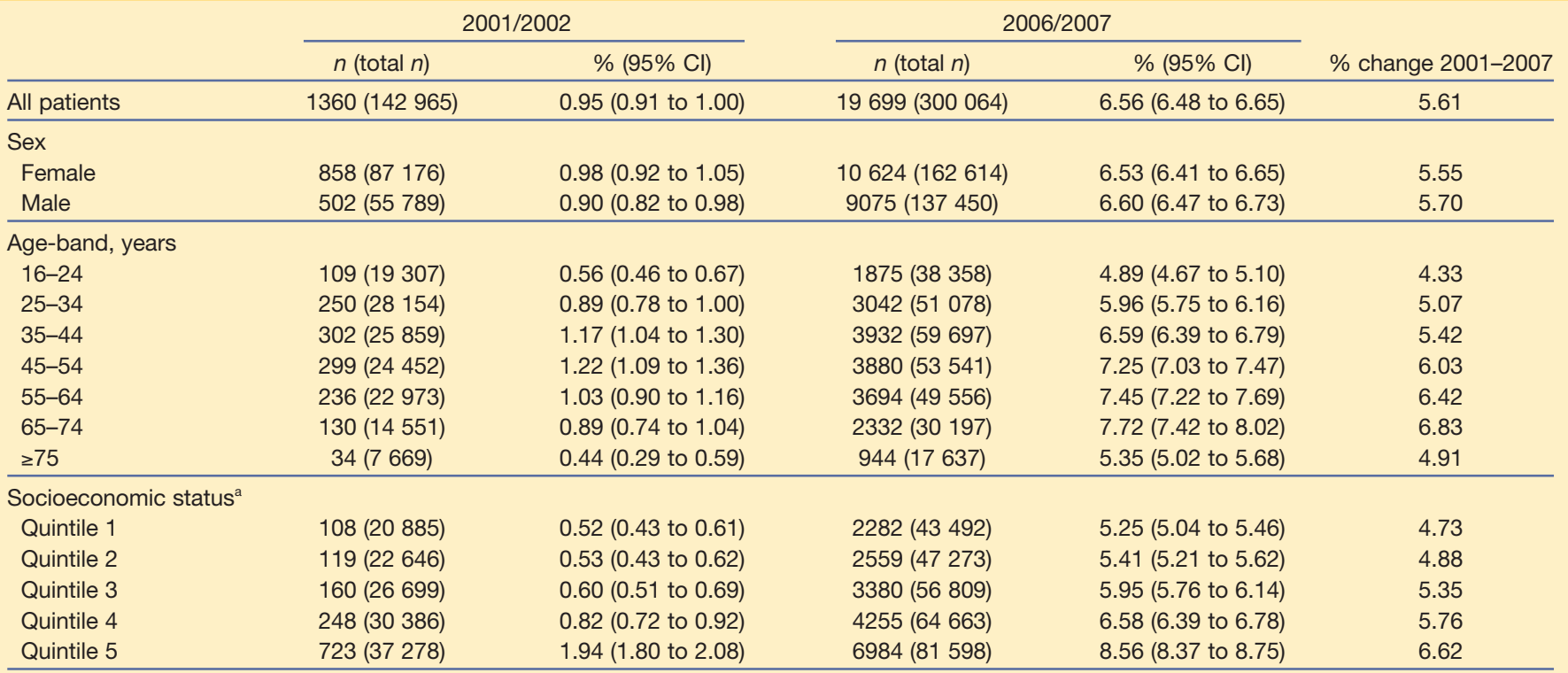

aHigher quintiles indicate areas of greater socioeconomic deprivation.

(Table 4). Between 2001/2002 and 2006/2007 there was a substantial increase in the proportion of newly recorded smokers offered smoking cessation advice $(P<0.001$; Figure 2$)$, particularly among the oldest patients (Table 3). Large increases in the number of patients referred to a specialist stop-smoking service were also found $(P<0.001$; Figure 2$)$, most particularly among older patients and those in the most deprived areas (Table 4).

\section{DISCUSSION}

\section{Summary of main findings}

This study, using routinely collected electronic data from one of the world's largest national datasets, found a significant decline in the rate of smoking from 2001 to 2007. Over the study period, increases occurred in the provision of smoking cessation advice to smokers and referral to specialist services. However, high rates of smoking continued among younger adults and those in the most 
socioeconomically deprived areas in the UK. Overall, the numbers of smokers in the UK in 2007 was estimated at 13.7 million.

\section{Strengths and limitations of the study}

The main strengths of this study include the interrogation of an extremely large nationally representative dataset and the use of data from primary care practices, where the majority of services are free at the point of care and the majority of people in the UK are registered. Also, all contributing practices are accustomed to electronically recording routine data and use the same computing system.

There are a number of limitations related to the use of routinely collected data from primary care, including improvements in recording over the study time period and a lack of any direct validation of smoking status in the QRESEARCH database. It is possible that decreases in the proportion of people found to smoke could be overestimated, due to a larger number of non-smokers being recorded over time. Similarly, it is possible that increases in the provision of smoking cessation advice and referral could be underestimated, if in the past only new smokers who were referred or given advice were recorded by general practice as opposed to any newly recorded smokers. It is also possible that the number of non-smokers has been underestimated. This may be as a result of the increasing numbers of smokers being referred to smoking cessation programmes, with some of these patients giving up in the short term, being recorded as non-smokers and then reverting back to smoking without being recorded as such. It is likely though that smoking status (where recorded) is accurate, ${ }^{16}$ and routine visits to practices by quality assurance and appraisal teams help to ensure the accuracy of practice-held electronic data that are relevant to the Quality and Outcomes Framework. ${ }^{17}$

Univariate analyses were carried out, and therefore it is possible that although trends over time are likely to be real, differences between groups of patients could be explained by demographic or comorbidity variations across the study period. The observational nature of this study also means that it is not possible to attribute directly the changes observed here to the introduction of government anti-smoking initiatives.

\section{Comparison with existing literature}

Large increases in the collection of clinical indicator data (such as smoking status) by GPs after the introduction of the new GMS contract have also been found in populations with cardiovascular disease. ${ }^{18-20}$ Although the proportion of adult smokers in the QRESEARCH dataset in 2001/2002 (28\%) and
$2006 / 2007$ (22\%) was slightly higher than that found in the General Household Survey (2002: 27\%; 2007: $21 \%),{ }^{1}$ and slightly higher than the Health Survey for England in 2002 (26\%), by 2007 the proportion of adult smokers in the QRESEARCH population was the same as in the Health Survey for England (22\%). ${ }^{21}$ It is also reassuring to note that the reported decrease in the rate of smoking $(6 \%)$ was similar to that reported in the General Household Survey. ${ }^{1}$ The mean rate of smoking in 2002 was also considerably lower than the mean rate of smoking reported in Europe $(33 \%),{ }^{22}$ but more than found in a national survey in the US $(21 \% ; 2005) .{ }^{23}$ The rate of smoking among the most affluent patients (14\%) in 2007 was lower than that found in non-manual groups in the English General Household Survey (16\%), and was considerably higher for the most deprived groups (34\%) when compared with manual workers (28\%). ${ }^{1}$

\section{Implications for future research and clinical practice}

The decline in the rate of smoking suggests that the UK has now achieved the overall threshold of $24 \%$ set out for smoking in the 2004 Public Service Agreement, ${ }^{24}$ and is near to achieving the 2010 Public Service Agreement target of $21 \% .{ }^{25}$ With the introduction of new laws in the UK to prohibit smoking in enclosed public places and workplaces, ${ }^{26}$ the rise in the minimum age of smoking to 18 years, and the introduction of pictorial images on cigarette packaging, it is hoped that rates of smoking will continue to fall. However, substantial socioeconomic and age group differences in smoking rates have continued, suggesting a need to reinvigorate and introduce new measures aimed at reducing smoking rates among patients in more socioeconomically deprived areas and younger people in the UK population. ${ }^{27}$ Such measures include the need for further targeting of resources to help increase the proportion of deprived and younger patients receiving smoking cessation advice, the continued limiting of cigarette advertisement and sponsorship, and the banning of point of sale displays and cigarette vending machines (which is known to have the highest influence on young smokers). ${ }^{28}$ The substantial improvements in the recording of smoking status in the UK population by general practice have coincided with the introduction of financial incentives as part of the new GMS contract in 2004. ${ }^{4}$ The continued collection of such data will help ensure that progress of any trends can be monitored and also provide a detailed picture of lifestyle risks in the UK.

A significant and important reduction in the numbers of UK smokers occurred between April 2001 and April 2007. However, although this is an 
improvement, comparatively high rates of smoking remain among younger adults and those who are the most socioeconomically deprived. Furthermore, there is the need to focus greater resources and efforts on targeting the prevention of smoking uptake in children and adolescents, and providing more resources for smoking cessation services among younger adults and in deprived areas.

\section{Funding body}

Colin R Simpson is supported by a health services and health of the public postdoctoral fellowship from the Chief Scientist Office of the Scottish Government (PDF/08/02)

\section{Ethics committee}

All data analyses were conducted using de-identified data and were subject to the QRESEARCH research governance processes

\section{Competing interests}

Julia Hippisley-Cox is Director of QRESEARCH (a not-forprofit organisation owned by the University of Nottingham and EMIS, commercial supplier of computer systems for $60 \%$ of GP practices in the UK). Colin R Simpson and Aziz Sheikh have no competing interests

\section{Acknowledgements}

We would like to record our thanks to the contributing EMIS practices and patients, and to EMIS for providing technical expertise in creating and maintaining QRESEARCH. We thank QRESEARCH staff for their contribution to data extraction, analysis, and presentation. These findings have been reported in A Summary of Public Health Indicators Using Electronic Data from Primary Care, ${ }^{9}$ which is published by the NHS Health and Social Care Information Centre.

\section{Discuss this article}

Contribute and read comments about this article on the Discussion Forum: http://www.rcgp.org.uk/bjgp-discuss

\section{REFERENCES}

1. Office for National Statistics. General household survey, 2006 Colchester, Essex: UK Data Archive, Office for National Statistics, Social Survey Division, 2009.

2. Department of Health. Smoking kills. A White Paper on tobacco. London: The Stationery Office, 1998.

3. Department of Health. The NHS plan: a plan for investment, a plan for reform. London: HMSO, 2000.

4. The NHS Confederation. Investing in general practice: the new general medical services contract. http://www.bma.org.uk/employmentandcontracts/independent_co ntractors/general_medical_services_contract/investinggp.jsp (accessed 7 Sep 2009).

5. Joossens L, Raw M. The Tobacco Control Scale: a new scale to measure country activity. Tob Control 2006; 15(3): 247-253.

6. Department of Health. Health inequalities: progress and next steps. London: HMSO, 2008.

7. North East Public Health Observatory. Occasional paper number 20. Are NHS stop smoking services reducing health inequalities in the north east of England? http://www.nepho.org.uk/index.php?c=1095 (accessed 1 Sep 2009).
8. Sheikh A, Hippisley-Cox J, Newton J, Fenty J. Trends in national incidence, lifetime prevalence and adrenaline prescribing for anaphylaxis in England. J R Soc Med 2008; 101(3): 139-435.

9. QRESEARCH and the Information Centre for Health and Social Care. A summary of public health indicators using electronic data from primary care. Nottingham: QRESEARCH, 2008.

10. Ghouri N, Hippisley-Cox J, Newton J, Sheikh A. Trends in the epidemiology and prescribing of medication for allergic rhinitis in England. J R Soc Med 2008; 101(9): 466-472.

11. Simpson CR, Newton J, Hippisley-Cox J, Sheikh A. Incidence and prevalence of multiple allergic disorders recorded in a national primary care database. J R Soc Med 2008; 101(11): 558-563.

12. Simpson CR, Newton J, Hippisley-Cox J, Sheikh A. Trends in the epidemiology and prescribing of medication for eczema in England. J R Soc Med 2009; 102(3): 108-117.

13. Hippisley-Cox J, Vinogradova Y, Coupland C, Pringle M. Comparison of key practice characteristics between general practices in England and Wales and general practices in the QRESEARCH database. Report to the Health and Social Care Information Centre. University of Nottingham: QRESEARCH, 2005.

14. QRESEARCH. The QRESEARCH database. Available from: http://www.qresearch.org (accessed 1 Sep 2009).

15. Department of Health. Population estimates for UK, England and Wales, Scotland and Northern Ireland.

http://www.statistics.gov.uk/statbase/Product.asp?vlnk=601\&More $=\mathrm{N}$ (accessed 1 Sep 2009).

16. Mant J, Murphy M, Rose P, Vessey M. The accuracy of general practitioner records of smoking and alcohol use: comparison with patient questionnaires. J Public Health Med 2000; 22(2): 198-201.

17. Department of Health. The Quality and Outcomes Framework guidance. London: The Department of Health, 2004.

18. Simpson CR, Hannaford PC, Lefevre K, Williams D. The effect of the UK incentive-based contract on the management of patients with stroke in primary care. Stroke 2006; 37(9): 2354-2360.

19. McGovern MP, Boroujerdi MA, Taylor MW, et al. The effect of the UK incentive-based contract on the management of patients with coronary heart disease in primary care. Fam Pract 2008; 25(1): 33-39.

20. McGovern MP, Williams DJ, Hannaford PC, et al. Introduction of a new incentive target based contract for family physicians in the United Kingdom: good for older patients with diabetes but less good for women? Diabet Med 2008; 25(9): 1083-1089.

21. The Information Centre for Health and Social Care. Health Survey for England 2007: latest trends. http://www.ic.nhs.uk/statistics-anddata-collections/health-and-lifestyles-related-surveys/healthsurvey-for-england/health-survey-for-england-2007-latest-trends\%5Bns\%5D (accessed 1 Sept 2009).

22. Strong K, Guthold R, Lang J, et al. Tobacco use in the European region. Eur J Cancer Prev 2008; 17(2): 162-168.

23. Centers for Disease Control and Prevention. National Health Interview Survey (NHIS) 2005. Atlanta: Centers for Disease Control and Prevention US Department of Health and Human Services, 2005.

24. Her Majesty's Treasury. 2004 spending review. Public Service Agreements 2005-8. London, Her Majesty's Treasury, 2004.

25. The Department of Health. Spending Review 2004 Public Service Agreement. London: HMSO, 2004.

26. Chapman S. The future of smoke-free legislation. BMJ 2007; 335(7619): 521-522.

27. Wanless D. Securing good health for the whole population. London: HMSO, 2004.

28. Ling PM, Neilands TB, Glantz SA. Young adult smoking behaviour: a national survey. Am J Prev Med 2009; 36(5): 389-394. 